\title{
Technical Note \\ INSPECTORMAP: A Spatial Data Infrastructure Applied to the Maintenance of Solar Plants Using Free Satellite Imagery
}

\author{
Esteban Ruiz de Oña, María Sánchez-Aparicio (D), Susana Del Pozo (i) and Diego González-Aguilera *(i) \\ Department of Cartographic and Land Engineering, Higher Polytechnic School of Ávila, University of Salamanca, \\ Hornos Caleros 50, 05003 Ávila, Spain; estebanrdo@usal.es (E.R.d.O.); mar_sanchez1410@usal.es (M.S.-A.); \\ s.p.aguilera@usal.es (S.D.P.) \\ * Correspondence: daguilera@usal.es; Tel.: +34-920-353-500 (ext. 3820)
}

check for

updates

Citation: Ruiz de Oña, E.;

Sánchez-Aparicio, M.; Del Pozo, S.

González-Aguilera, D.

INSPECTORMAP: A Spatial Data

Infrastructure Applied to the

Maintenance of Solar Plants Using

Free Satellite Imagery. Appl. Sci. 2022,

12, 70. https://doi.org/10.3390/

app12010070

Academic Editor:

Luis Hernández-Callejo

Received: 2 December 2021

Accepted: 20 December 2021

Published: 22 December 2021

Publisher's Note: MDPI stays neutral with regard to jurisdictional claims in published maps and institutional affiliations.

Copyright: (C) 2021 by the authors. Licensee MDPI, Basel, Switzerland. This article is an open access article distributed under the terms and conditions of the Creative Commons Attribution (CC BY) license (https:// creativecommons.org/licenses/by/ $4.0 /)$
Abstract: Photovoltaic solar plants are one of the main facilities away from urban centers for the generation of clean energy. Since its appropriate maintenance ensures its suitable operation, optimizing their maintenance tasks in a preventive way is key. This article presents a spatial data infrastructure called INSPECTORMAP that, based on the analysis of free satellite images within the optical spectrum, can detect unusual vegetation and bodies of water in the vicinity of photovoltaic plants that can affect their correct operation. Thanks to the implementation of a monitoring and alert system, it is possible to know and map the status of the photovoltaic plant in terms of unusual coverages appearing, both natural and artificial, at any moment. Thus, maintenance workers would travel to the solar plant to carry out their maintenance tasks in this regard only when the system detects a risk.

Keywords: spatial data infrastructure; landsat-8; sentinel-2; risks; unattended maintenance; solar plants

\section{Introduction}

In the last decades, there has been an increase in world energy consumption motivated by population growth [1]. The data collected by The Global Energy Statistical Yearbook [2] indicate an average annual energy consumption growth of 2\% during the 2000-2018 period. The annual forecast from the International Energy Agency (IEA) indicates that this trend will continue to increase. According to the 2019 IEA report [3], by the year 2040 there, will be an increase in global energy demand of $24 \%$ due to the increase in the world population and the improvement of living standards of the newly industrialized and developing nations. Within energy consumption, electricity has grown the most. Based on data collected by the IEA in 2018, the total world electricity consumption is 24,738.9 TWh [4]. Current world energy policies are focused on increasing renewable resources for energy generation to combat climate change and its impacts [5]. To date, only $27 \%$ of all electrical energy comes from renewable energy sources [2]. Given the significant cost reduction associated with renewable energy generation technologies, wind and sun are currently the main renewable energy sources used for large-scale electricity generation [6,7].

In recent years, photovoltaic solar plants have experienced significant growth, largely motivated by the greater accessibility to solar resources throughout the world geography. This type of facilities can reach high powers, so they require large surface areas for their suitable installation. Bhadla Solar Park, located in India, is the largest solar park in the world occupying $57 \mathrm{~km}^{2}$ with a total electrical capacity of $2245 \mathrm{MW}$ [8]. Above $2000 \mathrm{MW}$, there are only the Huanghe hydroelectric park in Hainan (China) $[9,10]$, as well as the Pavagada photovoltaic solar park located in India [11,12].

Since these facilities cover large surfaces, their maintenance plays a key role for their correct operation and efficiency [13]. In this sense, remote sensing is a very useful technique. In recent years, many researchers have made use of drones to acquire thermal images of photovoltaic plants, mainly to know the status of the solar panels [14,15]. Li et al. 
showed how the application of artificial intelligence networks allows for automating this process [16]. Another important aspect regarding the maintenance of photovoltaic installations is the conditions of their surroundings. The earth's surface is subject to continuous changes of both natural and artificial origin. Regarding the changes caused naturally, the presence of small or large masses of vegetation or the accumulation of water in the vicinity of these facilities can negatively affect their proper operation. These are changes that require continuous monitoring. Although drones allow capturing images with high spatial resolution, they turn out to be an expensive alternative due to the need for an expert pilot and frequent flights. In addition, these devices have other weaknesses: (i) impossibility of flying with extreme weather conditions such as strong winds, large episodes of rain, or high temperatures; (ii) limitation when flying large areas due to the autonomy of their batteries; (iii) the need to have an expert drone flight operator who oversees planning and executing the flight, which increases costs. As an alternative to this robotic technology, there are earth observation satellites capable of monitoring the surroundings of photovoltaic facilities over time. Currently, large space agencies such as NASA (National Aeronautics and Space Administration) and ESA (European Space Agency) have different Earth observation missions that capture images of the Earth's surface [17]. These are images that not only stand out for their free nature but also for their temporal and spectral resolution. This type of satellite captures images every few days, within several regions of the electromagnetic spectrum, which allows the detection of different elements of the Earth's surface by means of different spectral indices [18].

To efficiently manage this information, given its type and quantity, systems with a great capacity both to process and display satellite images, as well as to store them, are required. Although common Geographic Information System (GIS) tools are of great help in this regard, the use of a spatial data infrastructure (SDI) is a great alternative [19]. These are easy-to-use web tools that allow to automate the download, storage, and processing of data without the need for a computer with a large graphic and storage capacity, since everything is done through the cloud. Likewise, the latest advances in the Open Data Cube (ODC) standards $[20,21]$ allow the integration and fusion of different satellite platforms and missions, improving and enhancing the analysis of different satellite products together.

Based on the above, this article shows how, thanks to the development of an SDI that feeds on free satellite images from the main world space agencies and under the ODC standard, the presence of water masses and the growth of vegetation in solar plants can be detected. After this introductory section, Section 2 presents the materials and methods used for the correct development of the application. Section 3 shows the experimental results, and finally, Section 4 will show the most significant conclusions of the study.

\section{Materials and Methods}

The SDI tool developed for the detection of water masses and vegetation changes in the vicinity of photovoltaic solar plants is based on Landat- 8 and Sentinel-2 satellite images, as well as their integration according to a Local Nested Grid (LNG) [21].

\subsection{Satellite Images to Monitor Earth Surface}

To continuously monitor the phenomena and changes that occur on the Earth's surface, space agencies have satellites in orbit that carry different sensors on board to acquire data in this regard. Regarding the physical-mathematical model that underlies the acquisition of satellite images, it should be noted that it encompasses the conjunction of several phases, considering the Earth/atmosphere interaction of radiation and the internal physical behavior of the sensors. Sentinel-2 and Landat- 8 images used in this paper are Level-2 products so that they are calibrated images with reflectance values at the bottom of the atmosphere [22,23]. Specifically, NASA and the United States Geological Survey (USGS), since 1972, has launched different Earth observation satellites under the name Landsat. Although Landsat-9 is the last satellite put into orbit (on 27 September 2021), Landsat- 8 is the last to offer its products to date. Landsat-9 will start offering its products in early 2022. 
Of the two instruments that Landsat-8 has on board, the OLI (Operational Land Imager) sensor captures images in different parts of the optical spectrum (Table 1) with a 16-day temporal resolution and a 12-bit radiometric resolution. Once Landsat-9 data begin to be offered, the temporal resolution offered by this constellation of satellites will be 8 days instead of 16 days.

Table 1. Main characteristics of the Landsat-8 OLI sensor.

\begin{tabular}{ccc}
\hline Bands & Wavelength Range $(\mu \mathrm{m})$ & Spatial Resolution $(\mathbf{m})$ \\
\hline B1-Coastal aerosol & $0.43-0.45$ & 30 \\
B2-Blue & $0.45-0.51$ & 30 \\
B3-Green & $0.53-0.59$ & 30 \\
B4-Red & $0.64-0.67$ & 30 \\
B5-NIR & $0.85-0.88$ & 30 \\
B6-SWIR 1 & $1.57-1.65$ & 30 \\
B7-SWIR 2 & $2.11-2.29$ & 30 \\
B8-Panchromatic & $0.50-0.68$ & 15 \\
B9-Cirrus & $1.36-1.38$ & 30 \\
\hline
\end{tabular}

In recent years, the European Space Agency (ESA) has become a reference space agency thanks to the Copernicus earth observation program, in which satellite data are the main source of information. With a total of six families of satellites, under the name Sentinel, ESA is able to monitor different important parameters to improve the environmental management. Specifically, the constellation Sentinel-2 (2A and 2B), thanks to its MSI sensor, captures data within the optical spectrum (Table 2) with a 5-day temporal and a 12-bit radiometric resolution.

Table 2. Main characteristics of the Sentinel-2 MSI sensor.

\begin{tabular}{ccc}
\hline Bands & Wavelength Range $(\mu \mathrm{m})$ & Spatial Resolution $(\mathbf{m})$ \\
\hline B1-Coastal aerosol & $0.43-0.45$ & 60 \\
B2-Blue & $0.45-0.52$ & 10 \\
B3-Green & $0.54-0.57$ & 10 \\
B4-Red & $0.65-0.68$ & 10 \\
B5-Red Edge 1 & $0.68-0.71$ & 20 \\
B6-Red Edge 2 & $0.73-0.74$ & 20 \\
B7-Red Edge 3 & $0.77-0.79$ & 20 \\
B8-NIR 1 & $0.78-0.90$ & 10 \\
B8A-NIR 2 & $0.85-0.87$ & 20 \\
B9-Water Vapor & $0.93-0.95$ & 60 \\
B10-Cirrus & $1.36-1.39$ & 60 \\
B11-SWIR 1 & $1.56-1.65$ & 20 \\
B12-SWIR 2 & $2.10-2.28$ & 20 \\
\hline
\end{tabular}

Regarding the physical-mathematical model that underlies the acquisition of satellite images, it should be noted that it encompasses the conjunction of several phases, considering the Earth/atmosphere interaction of radiation and the internal physical behavior of the sensors. Sentinel-2 and Landat-8 images used in this paper are Level-2 products so that they are calibrated images with reflectance values at the bottom of atmosphere [22,23].

Both NASA and ESA have their own online platforms for downloading data captured by the corresponding satellite instrument. Due to the need for up-to-date images to carry out suitable monitoring of the appearance of water bodies or anomalous vegetation surfaces in the plant surroundings, a continuous download of data is required. This results in a large amount of information to be managed. For this reason, a Python script has been developed so that it allows: (i) reporting the available Landast- 8 and Sentinel-2 Level-2 products along the photovoltaic plants by a proper query [24,25] to the downloading platforms, (ii) the automatic download of such information, (iii) the registration of the downloaded 
products in the system catalog, (iv) the automatic calculation of various spectral indexes for monitoring the status of the photovoltaic plants, $(\mathrm{v})$ the registration of these spectral indexes in the system catalog, and finally (vi) the publication of the spectral indexes in the SDI viewer through a map server. Likewise, the integration of Landsat- 8 and Sentinel-2 images has been carried out according to an LNG developed by the authors [20].

There is a great variety of spectral indices that are applicable to different areas of knowledge such as agriculture, hydrology, and forestry, among others [26-28]. For studies on vegetation in general, the Normalized Difference Vegetation Index (NDVI) is the most widely used since it allows estimating the quantity, quality, and growth of vegetation, thanks to the amount of radiation reflected by vegetation in the red and near infrared electromagnetic spectrum (Equation (1)) [29].

$$
N D V I=\frac{(N I R-R e d)}{(N I R+R e d)},
$$

representing NIR and Red the surface reflectance values at the near infrared and red bands, respectively.

This index takes values between -1 and 1 , where values close to zero indicate absence of vegetation or existence of dead vegetation, while values close to 1 indicate the existence of abundant and vigorous vegetation.

Regarding identifying water masses, the Normalized Differential Water Index (NDWI) is the most widely used spectral index [30]. Within the NDWI, there are different variants, although the most widely used, defined by the "McFeeters Method", considers the green and the near infrared bands (Equation (2)) [31].

$$
\text { NDWI }=\frac{(\text { Green }-N I R)}{(\text { Green }+ \text { NIR })},
$$

representing Green and NIR the surface reflectance values at the green and near infrared bands respectively.

The NDWI is a variant of the NDVI, in which the equation reverses the order of the NIR, and the red band is replaced by the green one. This relationship makes it possible to maximize the reflectance of the water when working with green wavelengths, minimizing the NIR reflectance of the water and maximizing the NIR reflectance of the vegetation. With this, it is possible to correctly delimit the water masses, as well as to analyze the degree of humidity of the vegetation. Such as the NDVI, the values that NDWI can take are between -1 and 1 , where values greater than 0 indicate bodies of water or areas with the presence of moisture.

Finally, it should be mentioned that satellite images may contain inaccuracies, mainly due to the resolution limitation of the capture sensors. While this type of uncertainty can be minimized using fuzzy image pre-processors [32], in this case, it is admissible since the target is the detection of significant changes in vegetation and bodies of water.

\subsection{Spatial Data Infrastructure}

Any SDI is made up of data, metadata, processes to transform and query the data, and standardized web services for interacting between them. These software components are distributed according to a client-server architecture model (Figure 1). Specifically, the SDI INSPECTORMAP is developed under the language of Php and JavaScript using "Laravel" as a framework.

Behind the server-side of INSPECTORMAP (Back End, Figure 1) there is a Python script that, in combination with a PostgreSQL database, allows characterizing the areas to be studied as well as downloading and processing on a GeoServer the corresponding set of Landsat-8 and Sentinel-2 images. Furthermore, this script integrates an LNG [20] to ensure a more efficient integration of both data sets. From the downloaded images, the script automatically calculates the NDVI and NDWI spectral indices to analyze the presence of 
vegetation and water bodies, as explained in the previous section. The result is stored on the server and consumed as Web Map Services (WMSs) to map the affected areas with different color scales and, as Web Feature Services (WFSs), to quantify the affected areas in $\mathrm{m}^{2}$.

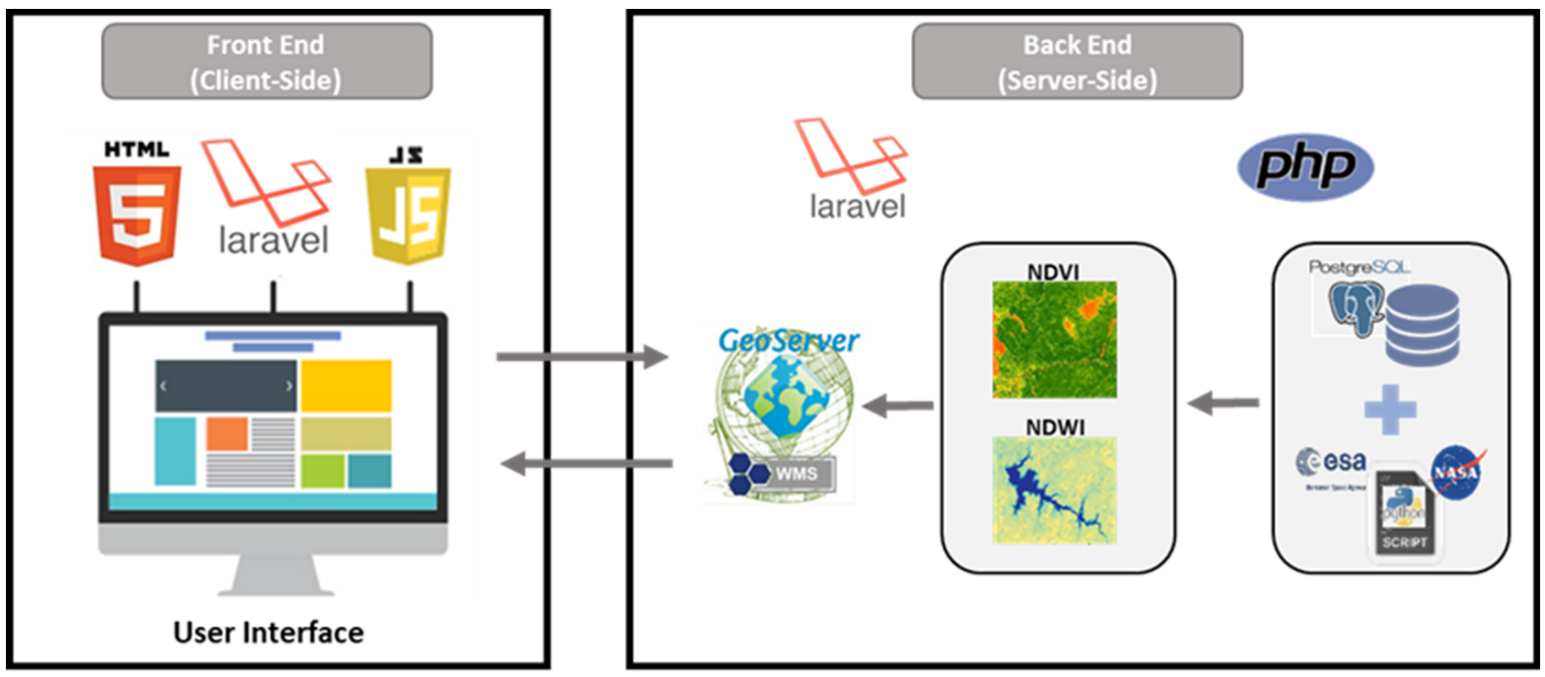

Figure 1. Workflow behind INSPECTORMAP, the Spatial Data Infrastructure proposed for the maintenance of photovoltaic plants.

The graphical interface of INSPECTORMAP (Front End, Figure 1) shows the results obtained in the server-side. It is a graphical interface that is mainly composed of three elements (Figure 2): (i) a geospatial information manager, (ii) a calendar, and (iii) a results viewer.

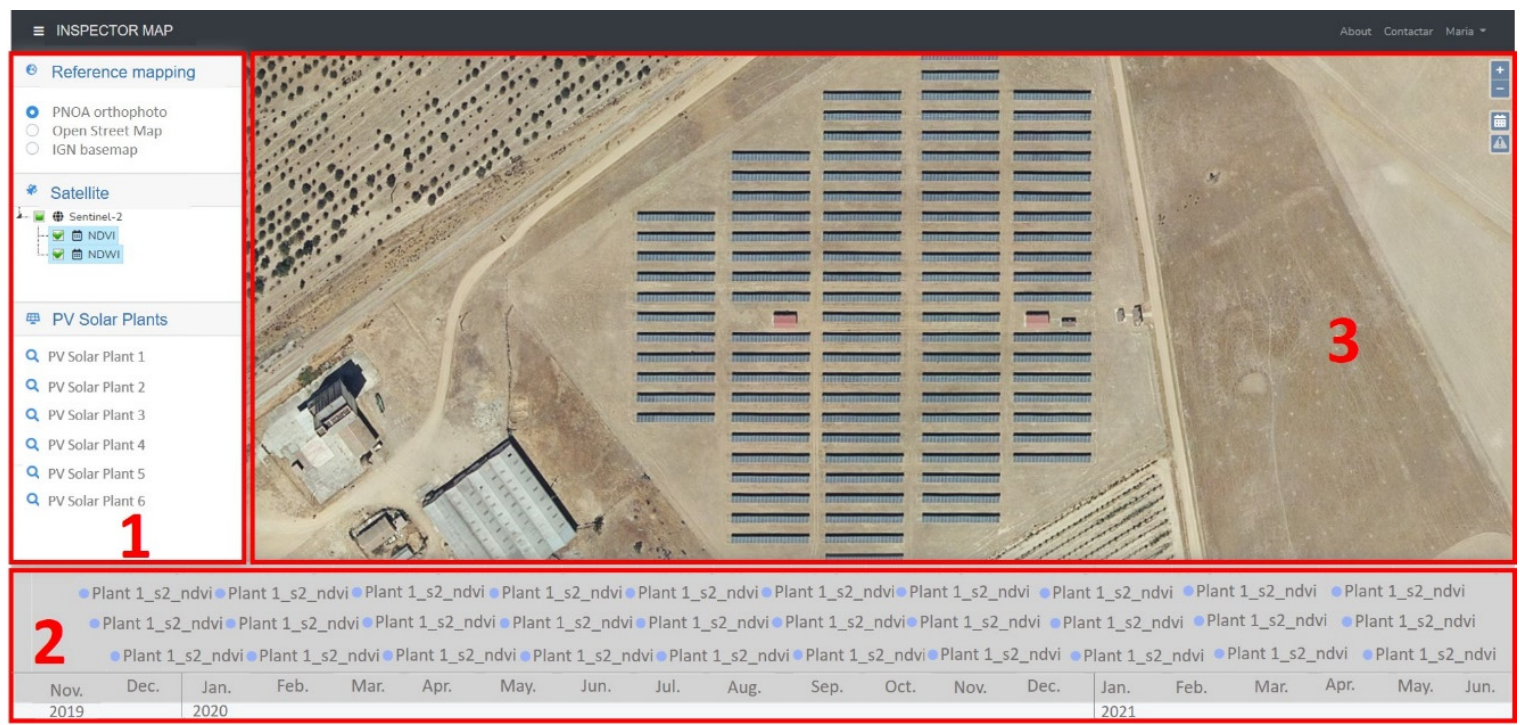

Figure 2. Graphic interface of the SDI INSPECTORMAP developed for the monitoring of photovoltaic plants.

\subsubsection{Geospatial Information Manager}

Given the large amount of geospatial information INSPECTORMAP manages, its interface allows, through the menu on the left, the user to select the type of reference base layer, the spectral index image, and the photovoltaic plant that he or she wishes to view (Figure 3). From among the reference base layers, the user can choose between: ortophotos from PNOA (Plan Nacional de Ortofotografía Aérea in Spanish, National Plan for Aerial 
Orthophotography in English) [33], Open Street Map products [34], or a base map of the National Geographic Institute [35]. For a quick location of the study areas, the tool offers a list of all monitored photovoltaic plants in such a way that the user can supervise each one with just one click.

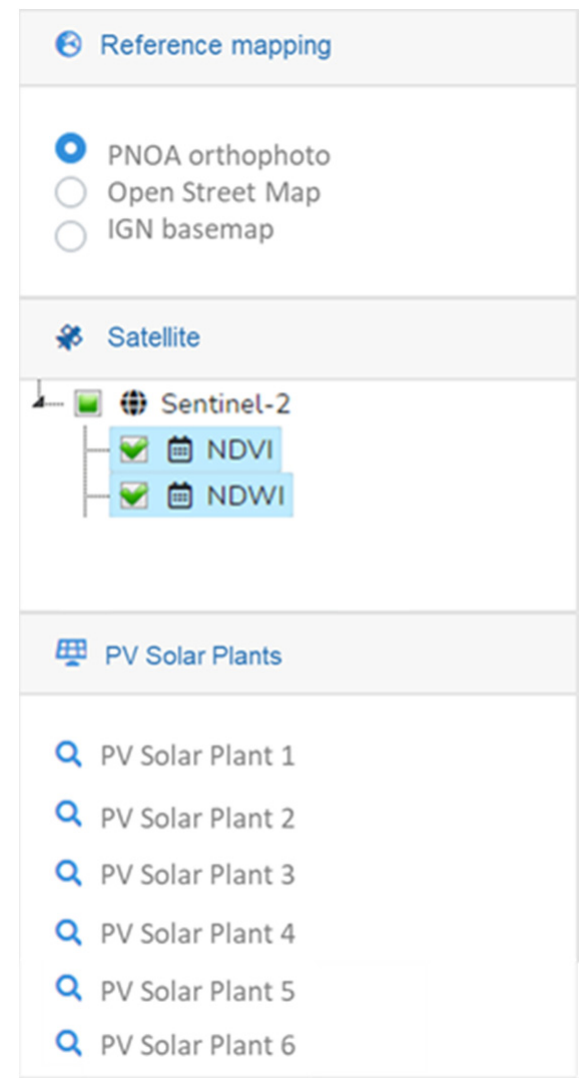

Figure 3. Geospatial information manager in detail.

\subsubsection{Calendar}

At the bottom of the interface, in the form of a calendar, the user can view the dates for which the spectral index images are available for the pre-selected photovoltaic plant (Figure 4). Furthermore, by clicking on each date, the product is automatically displayed in the results viewer.

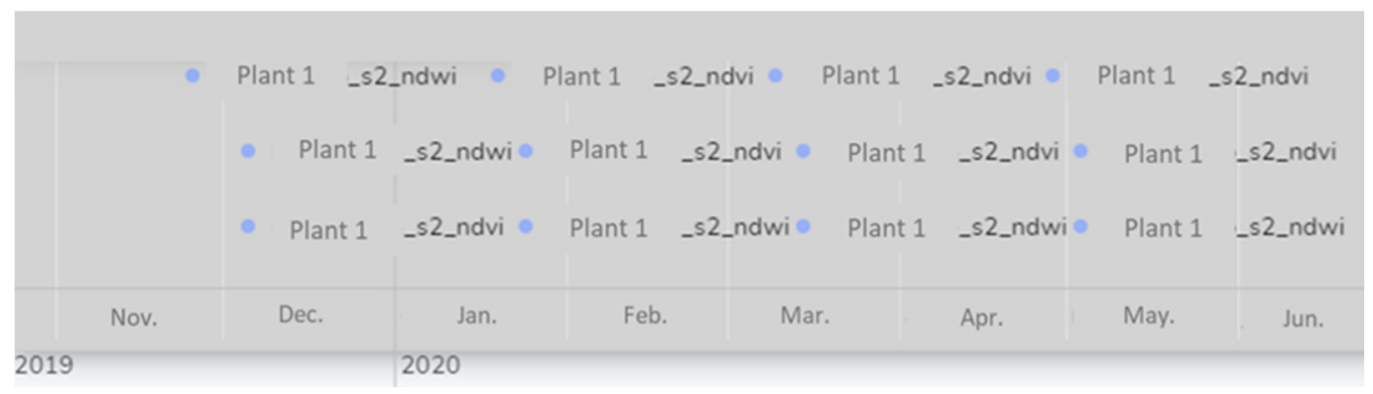

Figure 4. Calendar of the available satellite products.

\subsubsection{Results Viewer}

Located in the central part of the graphical interface is the results viewer. This space is destinated to display both the reference base layers and the spectral index images of the pre-selected photovoltaic plant. Thanks to this visualization, the user can qualitatively check the state of the vegetation and the existence of bodies of water in the vicinity of the 
photovoltaic plant for a specific date, as well as (2) quantify the possible risk derived from their existence (Figure 5). The NDVI and NDWI images are represented in a color scale bar to aid in the interpretation of the associated risk.

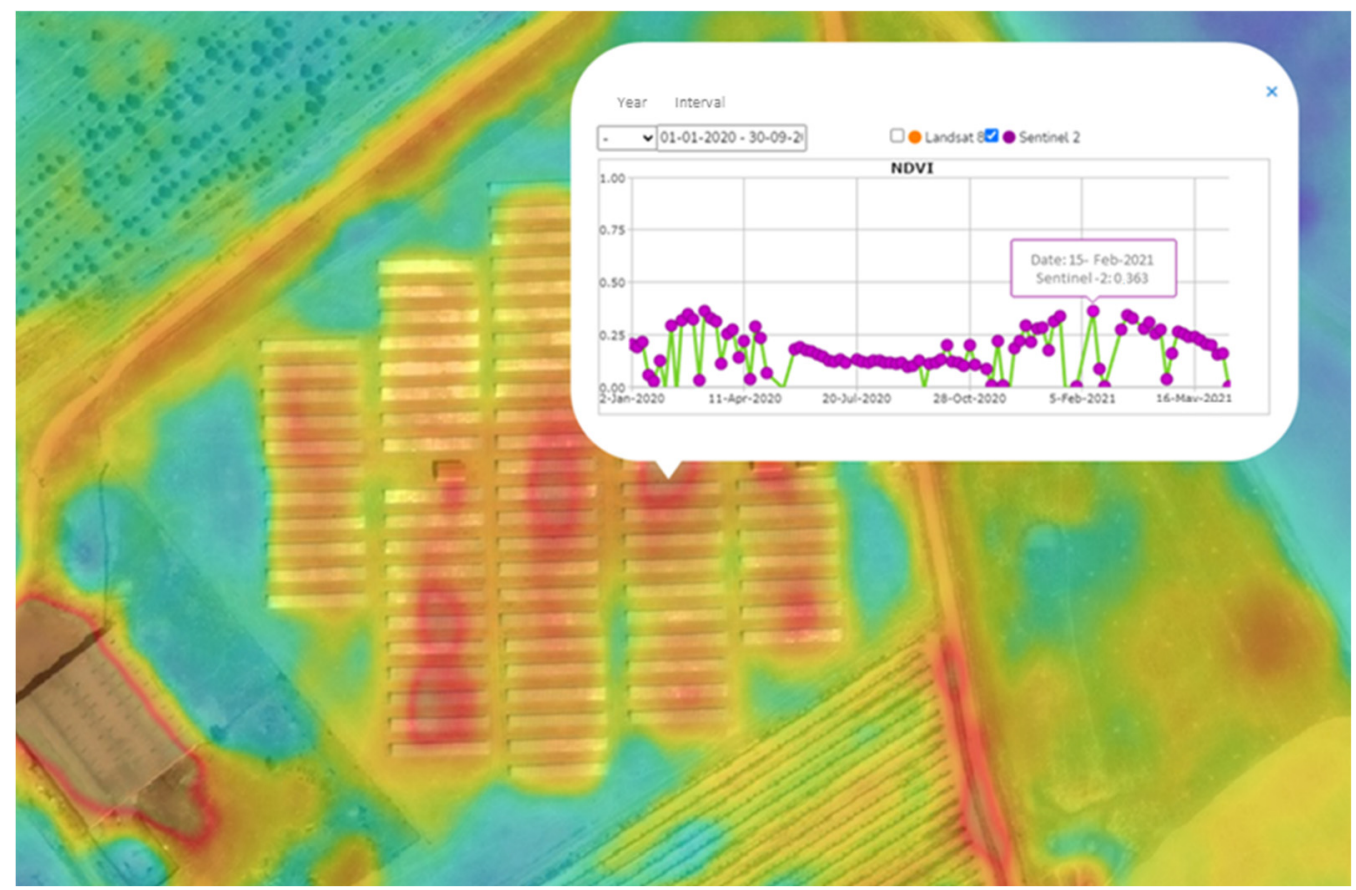

Figure 5. NDVI image display example of a photovoltaic solar plant for a given specific moment and the corresponding graph showing the NDVI variation over time for the selected pixel.

Thanks to an alert system implemented, the user can quickly detect if any of the photovoltaic plants included in the system have an atypical growth of vegetation or water surface in the vicinity by visualizing the affected areas as well as quantifying their surface in $\mathrm{m}^{2}$ (Figure 6). In addition, this system allows for generating a report in pdf format with the most relevant information on the risk detected and the suggestions for the maintenance operator (Figure 7).

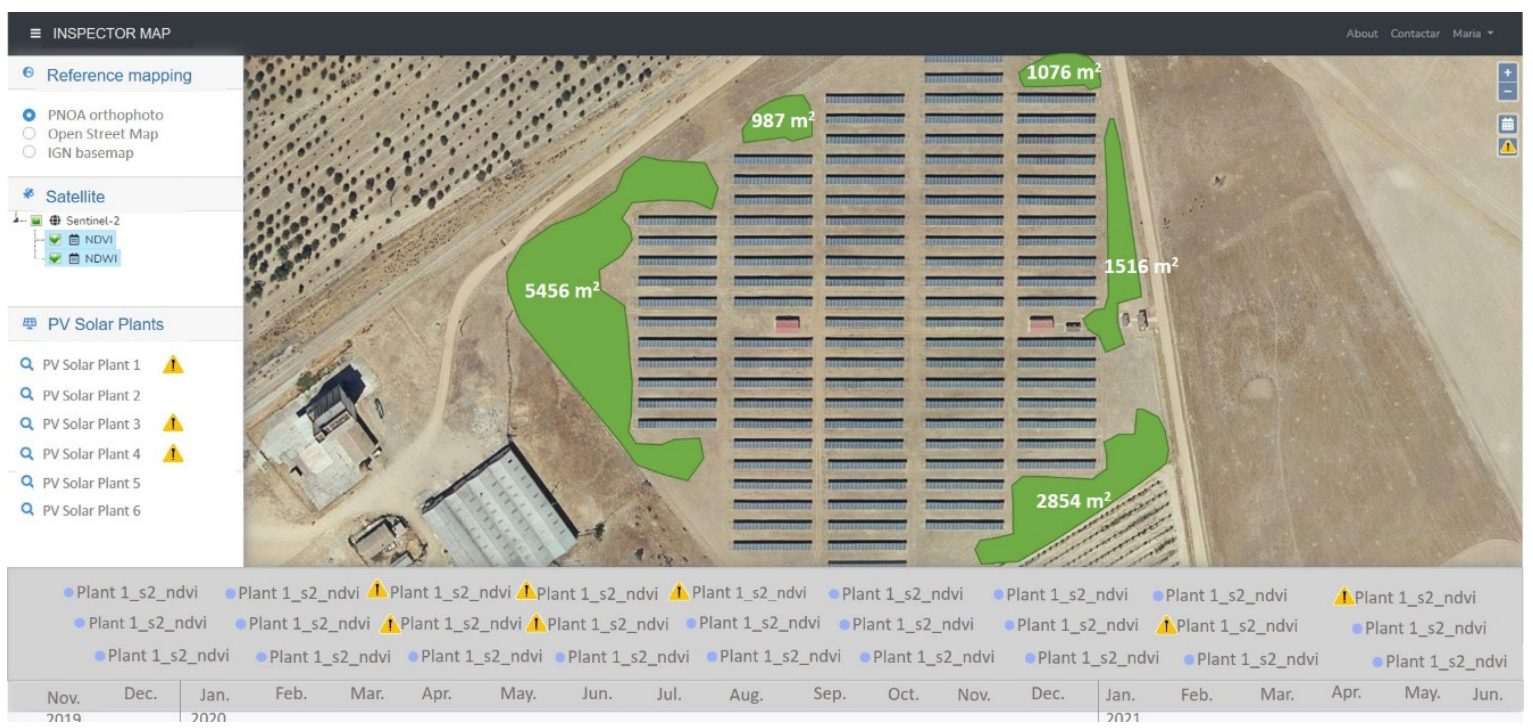

Figure 6. Visualization of results after activating the alert system in one of the photovoltaic solar plants included in the system. 


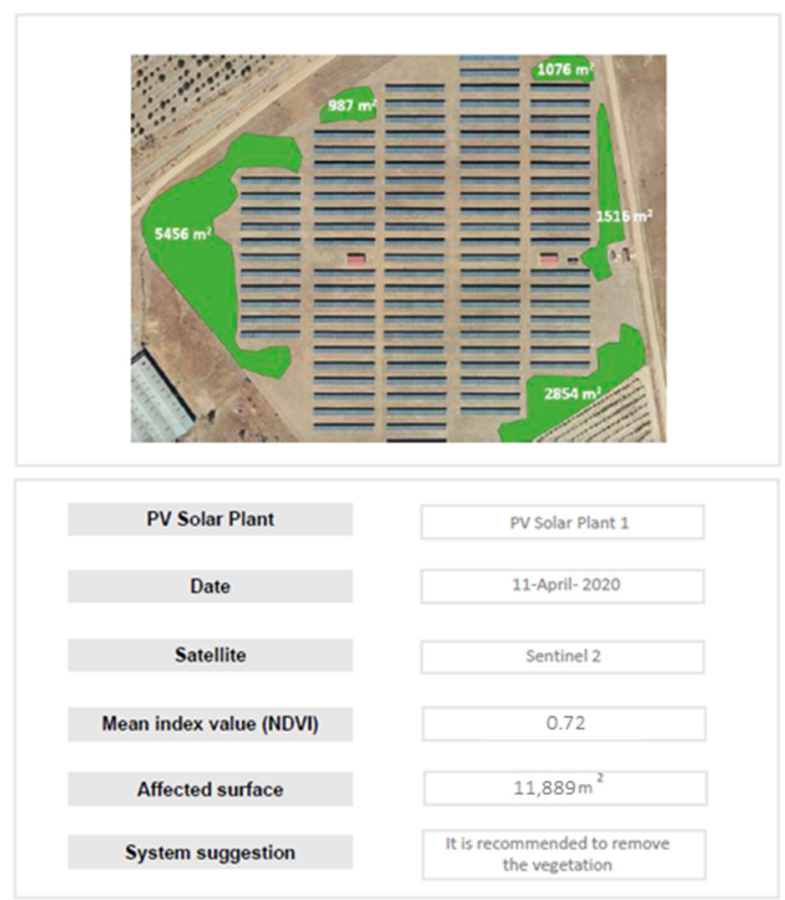

Figure 7. Standard report generated by the SDI INSPECTORMAP when the alert system is activated.

\section{Experimental Results}

Since the maintenance of photovoltaic solar plants does not require the daily presence of an operator, in many cases, these facilities are neglected, operating in a non-optimal way. In this sense, INSPECTORMAP allows for detecting risks that may negatively affect the operation of the photovoltaic installation, which allows for optimizing the movements of maintenance workers. Thus, the operator in charge of checking the state of the solar plant surroundings will only appear before a real risk due to the growth of vegetation or the presence of water masses. The presence of large bodies of water or high levels of humidity in the soil can negatively affect the foundations of the facilities. In addition, the presence of water bodies can make accessibility to the plant difficult. This problem also occurs due to the existence of large vegetation in the vicinity. However, the presence of vegetation not only affects the accessibility, but also the performance of the installation itself. Large vegetation creates shadows on the solar panels, preventing solar radiation from striking the photovoltaic panels. In addition, the presence of vegetation is an attraction for animals and insects, which increases the presence of excrement on the solar panels, reducing their performance.

To verify the correct operation of the SDI INSPECTORMAP and to corroborate its usefulness, six photovoltaic plants located in Spain subjected to different conditions have been analyzed (Figure 8).

\subsection{Study Cases}

The first plant analyzed (Figure 8a) is a photovoltaic plant located in an area categorized as grassland, where the solar panels are grouped in two areas separated by a building occupying an area of $62,808 \mathrm{~m}^{2}$. The adjacent plots are lands with the presence of trees.

The second plant (Figure $8 b$ ) has an area of $13,254 \mathrm{~m}^{2}$. It is a photovoltaic plant that is characterized by the proximity between their solar panels. Regarding the vegetation, the adjoining plots are characterized by being grasslands.

Regarding the third photovoltaic plant (Figure 8c), it occupies an area of $29,271 \mathrm{~m}^{2}$, in which there are areas with great spacing between groups of panels. From the vegetation 
point of view, the area where the solar panels are installed is a grass area, while the plots adjacent to the installation are arable plots.

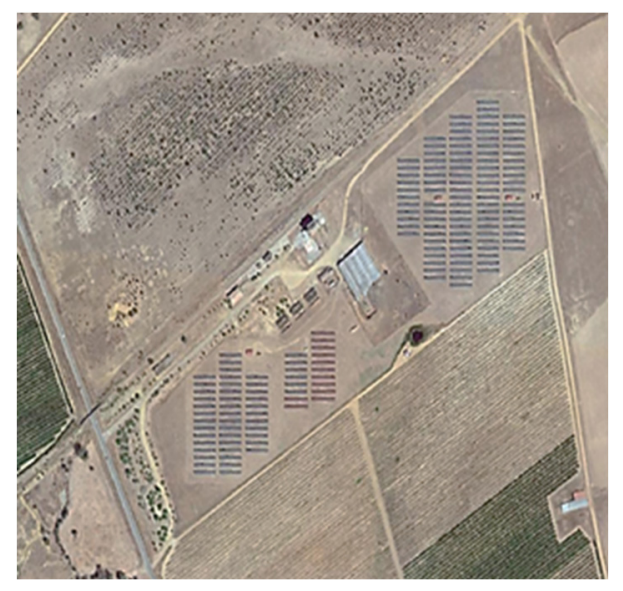

(a)

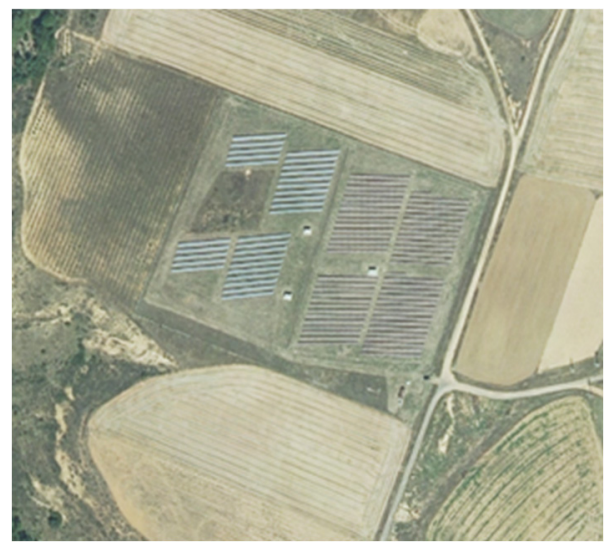

(c)

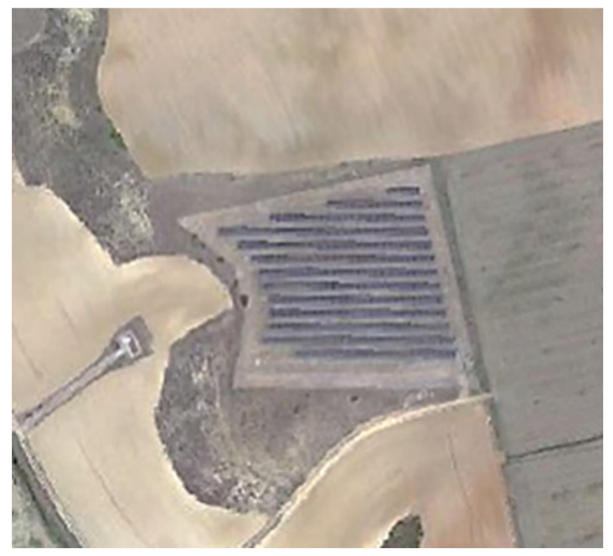

(e)

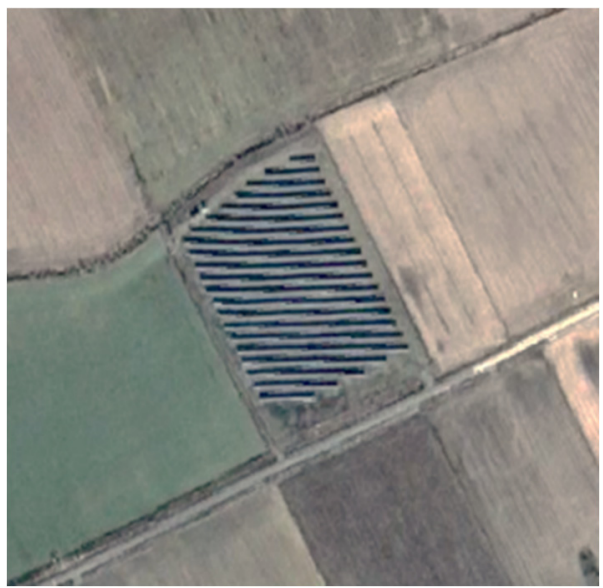

(b)

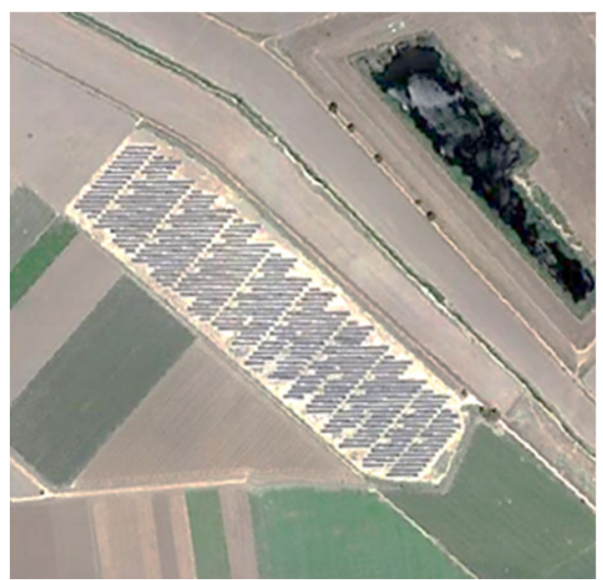

(d)

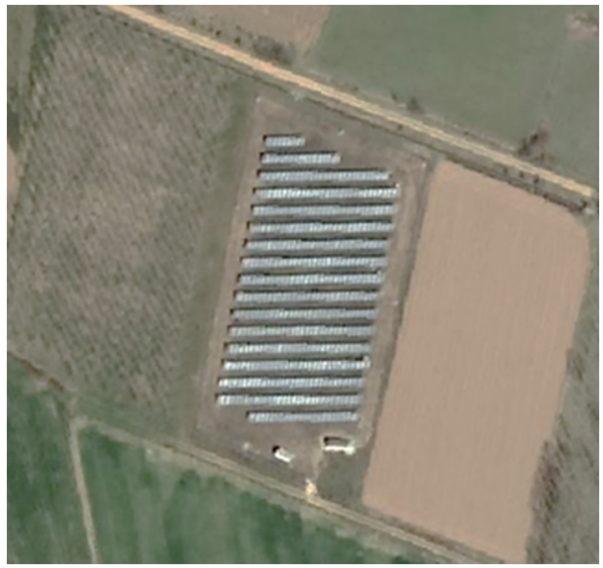

$(\mathbf{f})$

Figure 8. Photovoltaic plants analyzed with INSPECTORMAP to validate the tool performance: (a) plant 1, (b) plant 2, (c) plant 3, (d) plant 4, (e) plant 5, and (f) plant 6.

The fourth photovoltaic plant (Figure 8d) is the one with the largest surface area $\left(155,204 \mathrm{~m}^{2}\right)$. Unlike the rest of the solar plants, this one is in an irrigated arable plot. 
For its part, the fifth photovoltaic plant (Figure 8e) occupies an area of $11,753 \mathrm{~m}^{2}$ and it is located on an arable plot. The vegetation surrounding the plant is characterized by wooded and arable areas.

Finally, the sixth photovoltaic plant analyzed (Figure 8f) occupies an area of $5303 \mathrm{~m}^{2}$ and it is characterized by being located on a plot of grass. The adjoining parcel on the left has a wooded area with tall trees, while the adjoining parcel on the right corresponds with an arable land.

\subsection{Results and Discussion}

This section shows the results produced by the SDI INSPECTORMAP, which allow for the interpretation of the possible existing risks by a non-expert user. The user would be able to identify, through two ways, those areas where vegetation can be a problem for the operation of the solar installation: by means of (1) mapping the vigor of the vegetation at a given instant of time and the computation of the plant surface that would require to be eliminated, or through (2) the multitemporal analysis of the vegetation activity. Both ways are based on the calculation of the NDVI. In addition, and thanks to the NDWI map, it will allow to detect bodies of water that could affect the performance of the installations.

\subsubsection{Mapping the Vigor of Vegetation at a Given Instant of Time}

On the one hand, the tool displays, for a chosen date, the NDVI map the colors closer to brown indicate the absence of vegetation while the blue colors indicate the existence of vegetation with great vigor. Figure 9 shows the NDVI maps of the six plants analyzed during the month of May.

As previously stated, the six photovoltaic plants have in common that they are surrounded by grass. The maximum vigor of naturally grown grass (not watered) usually occurs between the months of April and May in the northern hemisphere. As a generic criterion, when the NDVI exceeds 0.70 [19], it is considered that the vegetation has sufficiently high vigor. Thus, for this specific application, this will be indicative of the need for maintenance tasks to eliminate it. In all cases (Figure 9), there is a percentage of vegetation that should be removed. It should be noted that, in plant 6, unlike the rest of the solar plants, the area where the solar panels are installed has a bluish-green hue while in the rest of the solar plants it has a reddish hue. This is not due to the presence of vegetation between panels, but to their great separation and the presence of vegetation with a notable vigor in the surroundings.

According to the alert system implemented, plants 1, 3, 4, and 6 are the ones with the largest area of vegetation to be removed: $54,418 \mathrm{~m}^{2}, 4486 \mathrm{~m}^{2}, 27,293 \mathrm{~m}^{2}$, and $5100 \mathrm{~m}^{2}$, respectively (Figure 10). For these cases, the NDVI value of the areas in need of maintenance have a mean value greater than 0.70 ; specifically, $0.76,0.73,0.79$, and 0.81 , respectively.

\subsubsection{Multitemporal Analysis of the Vegetation Activity}

The NDVI graphs are the other option with which the INSPECTORMAP tool allows to know the evolution of the vegetation. Unlike static NDVI maps, NDVI graphs allow for knowing the activity and growth of vegetation over a period of time. It is a very interesting alternative to know the behavior of the vegetation over time and plan the possible maintenance tasks. As can be seen in Figure 11, for each of the photovoltaic plants analyzed, a moment of maximum growth and vigor of the vegetation is always appreciated. Depending on the type of plant, this behavior will vary throughout the year. It is worth mentioning that the value of NDVI on cloudy days decreases sharply, hence all the sharp drops in the charts. All those graphs that represent the vegetative activity of the existing grass between the solar panels (Figure 11a,c,e) show a similar behavior, since during the months of June, July, and August there is either no vegetation (Figure 11e) or it is dry (Figure 11a,c). Although Figure 11b shows a totally different behavior, the vegetation on the plot is also grass. On the contrary, in the case of Figure 11d, the behavior of a vegetation characterized by being watered is represented where the NDVI presents a high value due 
to the vigor and humidity of the crop. Similarly, the plot to the left of the plant 6 exhibits high NDVI from April to October due to the vigor of the vegetation and its humidity.

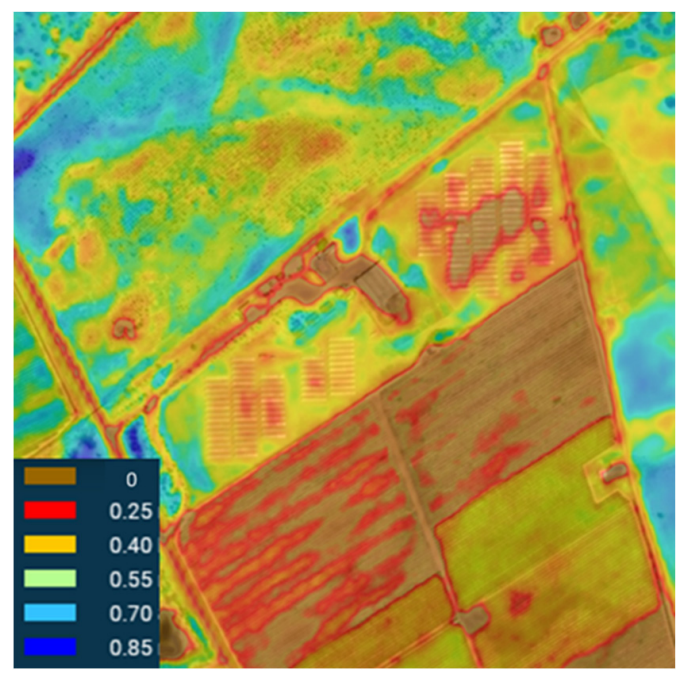

(a)

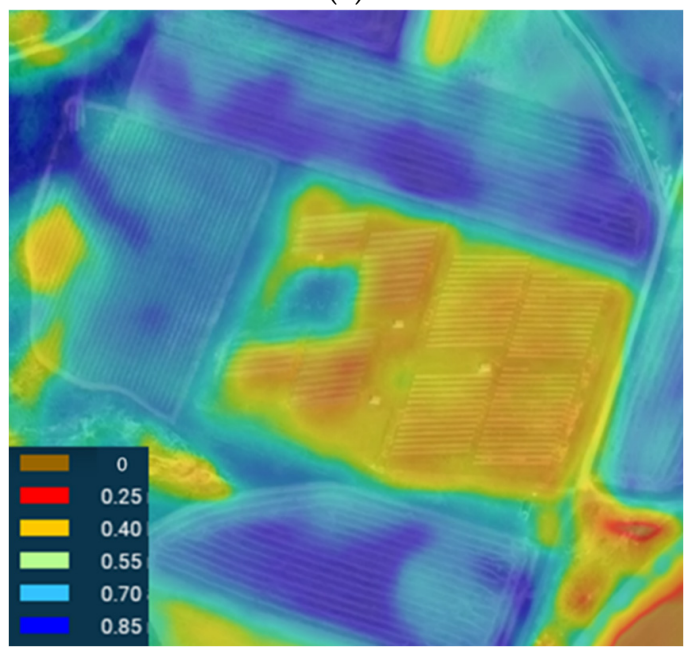

(c)

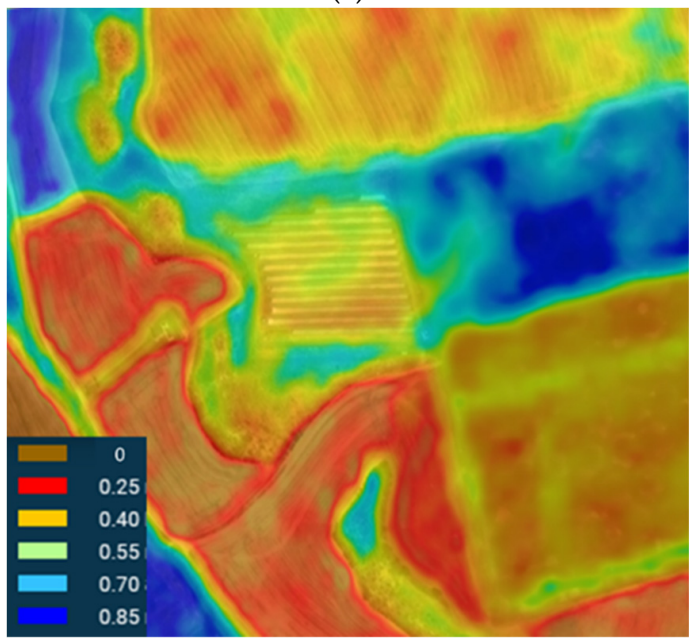

(e)

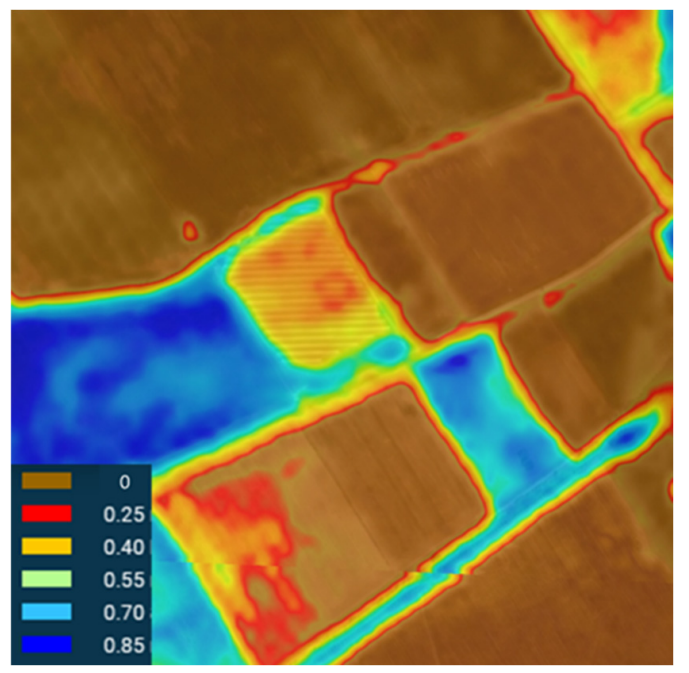

(b)

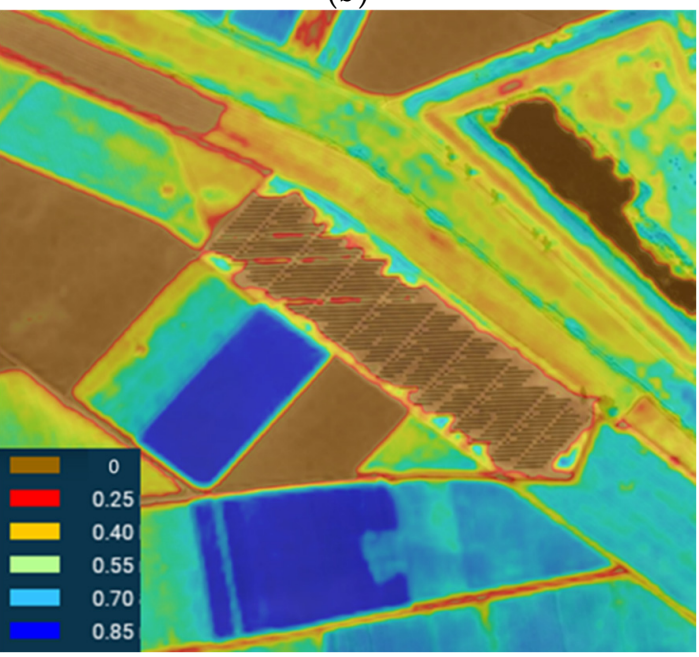

(d)

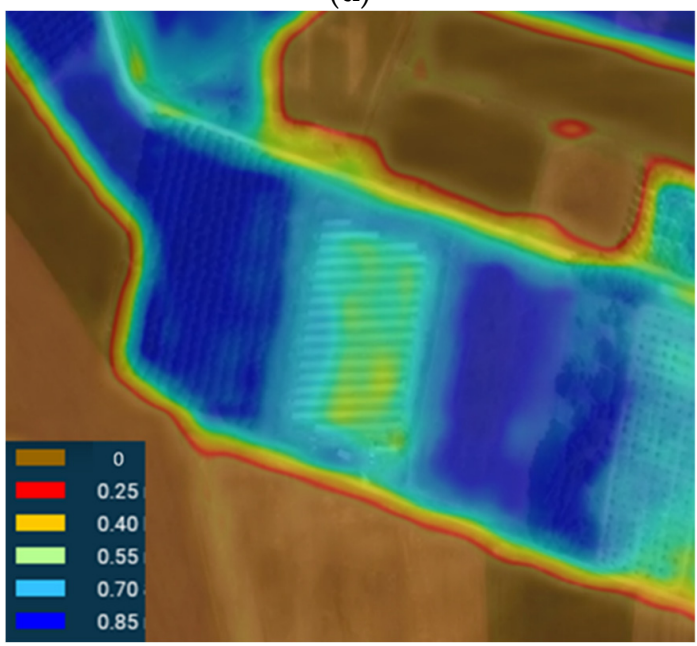

(f)

Figure 9. Graphic representation of the state of the vegetation through the NDVI for the different case studies in the month of May: (a) plant 1, (b) plant 2, (c) plant 3, (d) plant 4, (e) plant 5, and (f) plant 6. 


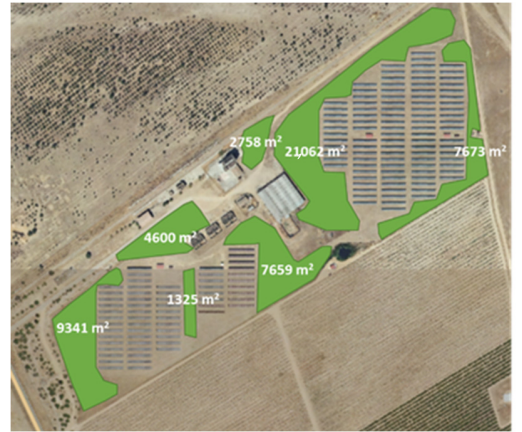

(a)

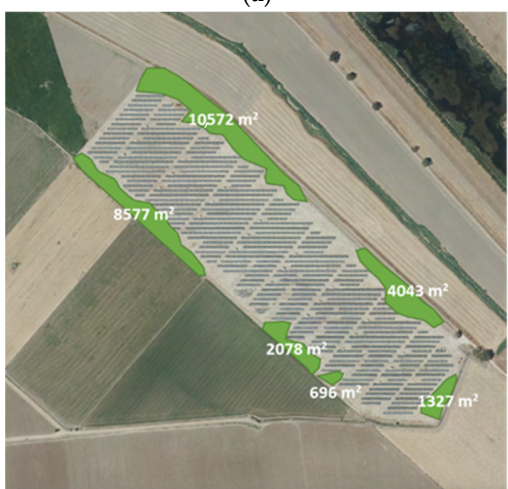

(c)

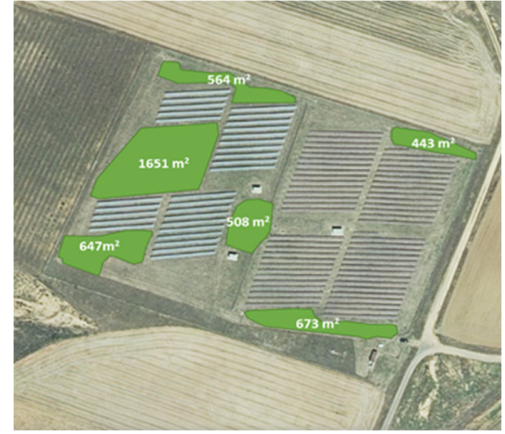

(b)

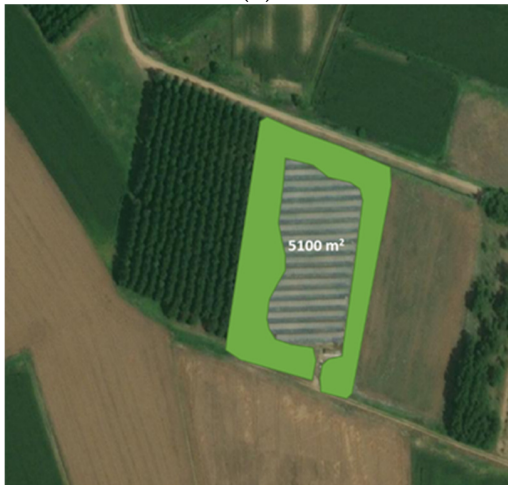

(d)

Figure 10. Areas detected and quantified by the INSPECTORMAP alert system for the dates that reveal greater vegetal vigor: (a) plant 1 , (b) plant 3, (c) plant 4, and (d) plant 6 .

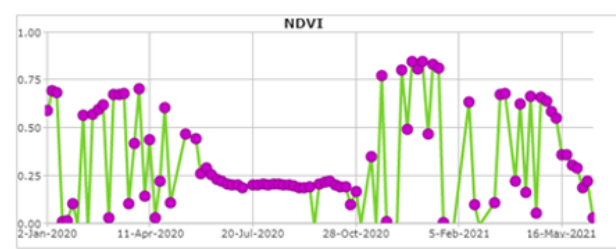

(a)

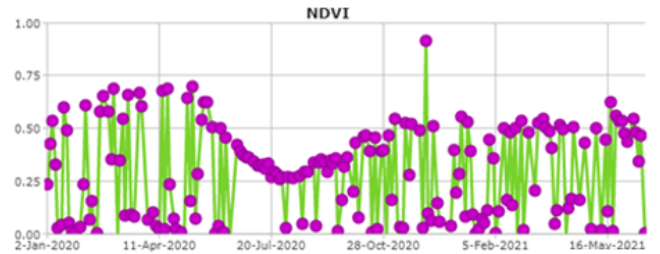

(c)

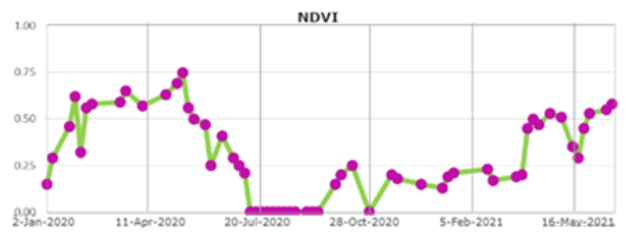

(e)

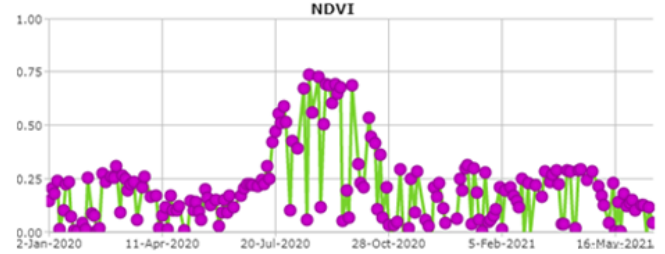

(b)

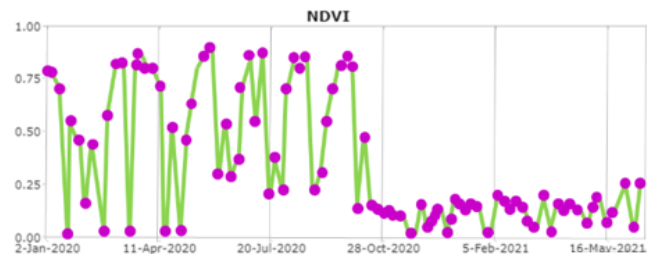

(d)

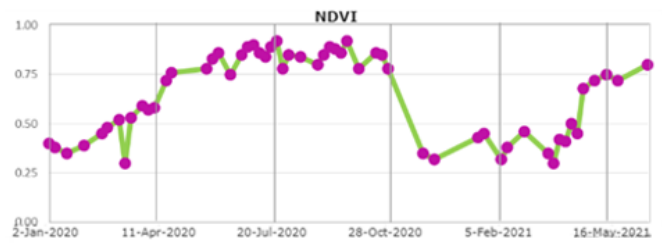

(f)

Figure 11. Vegetative activity through time in the vicinity of the photovoltaic plants analyzed by means of multitemporal NDVI graphs: (a) of the vegetation between the solar panels, (b) of the vegetation present in the adjacent right plot, (c) of the area without the presence of solar panels within the installation plot, (d) of the vegetation of the lower triangular plot, $€$ of the vegetation surrounding the solar installation, (f) of the vegetation of the plot located to the left of the installation. 


\subsubsection{Mapping the Water Bodies at a Given Instant of Time}

Solar installations are generally located in places away from large bodies of water such as rivers, lakes, or reservoirs. Sometimes, they are in areas close to water ponds that do not endanger the installation because they are far enough away (Figure 12).

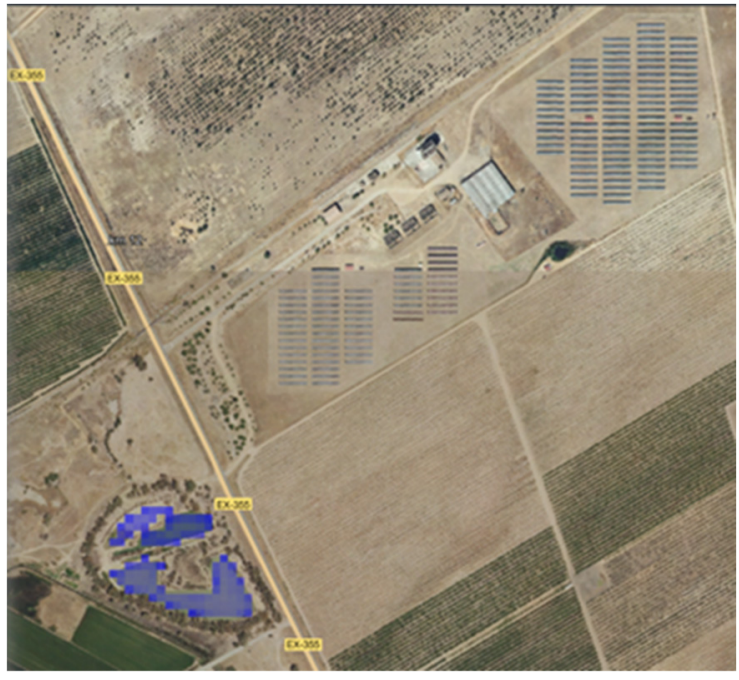

(a)

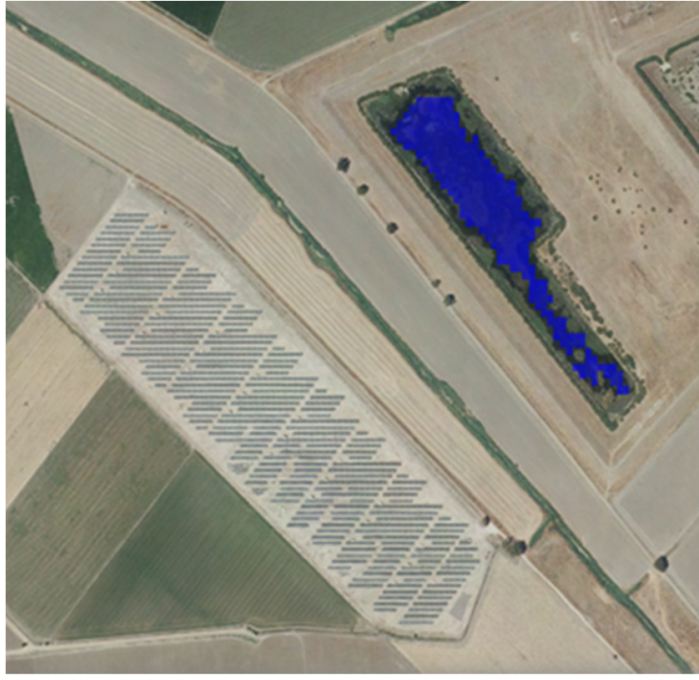

(b)

Figure 12. Water ponds detected with the NDWI index in the surroundings of (a) plant 1, and (b) plant 4 .

However, it is becoming more and more frequent to find episodes of heavy rains that can cause the accumulation of water, which could endanger the correct operation of this type of facility. An example of this occurred on plant 1 during a heavy rain episode during October 2020. The alert system detected a body of water with an area of $2134 \mathrm{~m}^{2}$ that not only limited the accessibility to the plant but could have put the installation in risk (Figure 13).

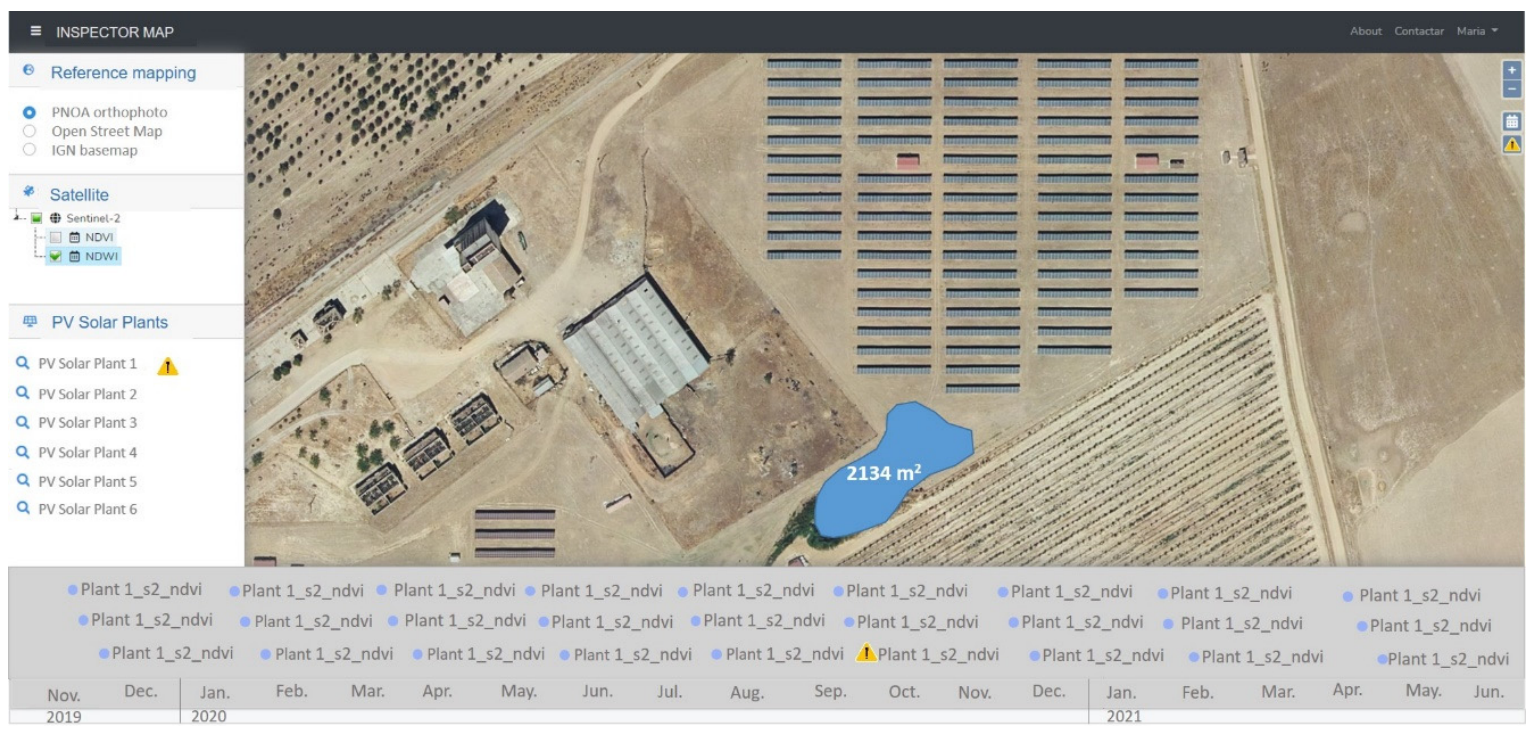

Figure 13. Body of water detected on plant 1 by the INSPECTORMAP alert system during an episode of heavy rain.

Although the NDWI is the most widely used spectral index for the detection of water masses, many authors are working on the development of new spectral indices. An example 
of this is [36], who developed an SWI index for the detection of water masses using different spectral bands of Sentinel-2 (Equation (3)).

$$
S W I=\frac{\text { Rededge } 1-\text { SWIR } 1}{\text { Rededge } 1+\text { SWIR } 1},
$$

While in the case of NDWI all the pixels are part of the water body, in the case of SWI there are "false positive" pixels (Figure 14c). When quantifying the area affected by the water body using the NDWI on plant 4 , it is obtained that with a 10-m resolution image the value is $31,166 \mathrm{~m}^{2}$ and with a $20-\mathrm{m}$ resolution the value drops to $27,171 \mathrm{~m}^{2}$. The area affected by water when applying the SWI index almost doubles, obtaining a value of $43,154 \mathrm{~m}^{2}$.

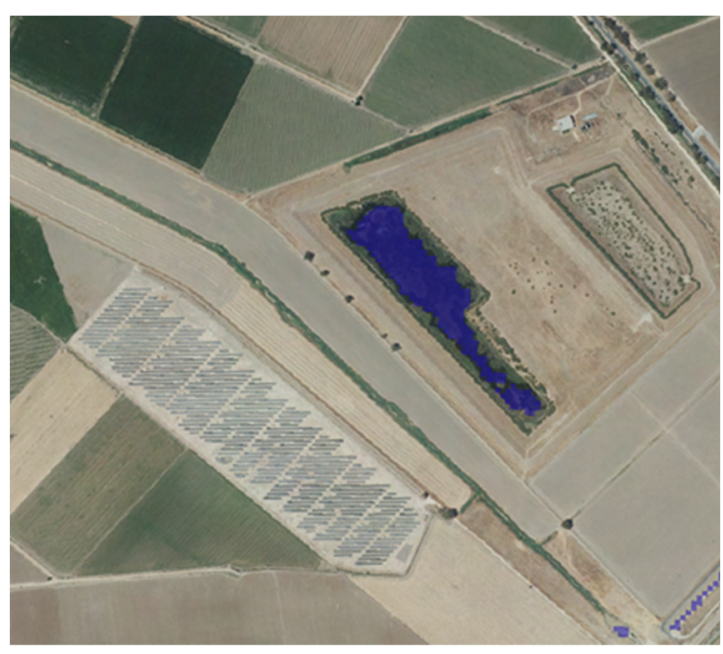

(a)

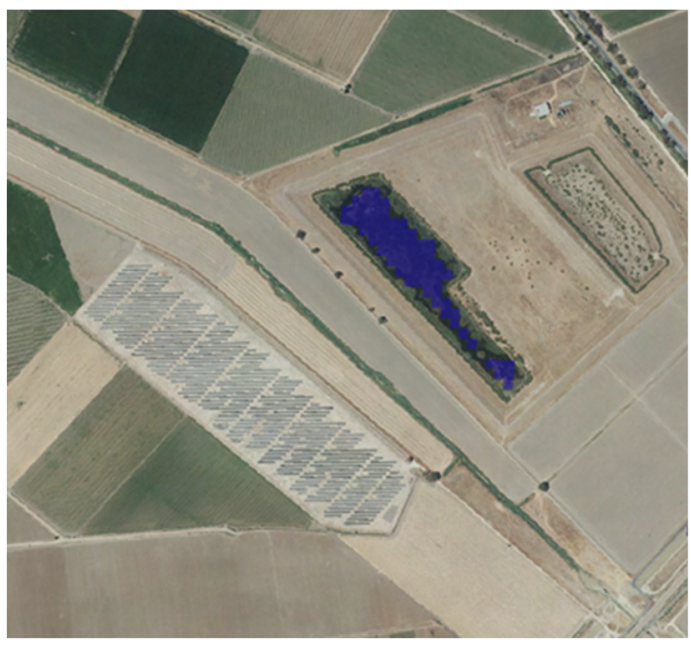

(b)

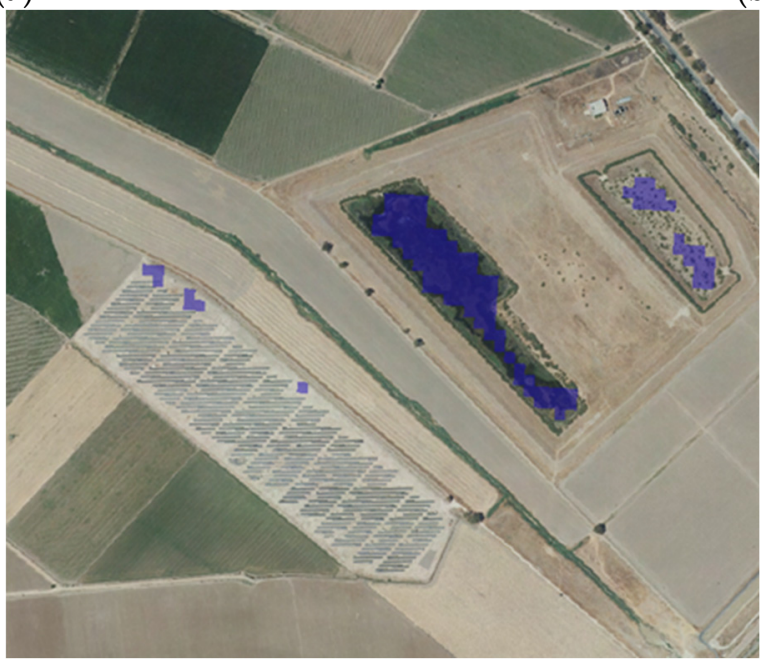

(c)

Figure 14. Bodies of water detected in the vicinity of plant 4 for a specific instant of time based on: (a) the NDWI with a 10-m spatial resolution, (b) the NDWI with a 20-m spatial resolution, and (c) the SWI with a 20-m spatial resolution.

\section{Conclusions}

The maintenance of photovoltaic solar plants plays a key role in terms of their performance and useful life. The INSPECTORMAP tool presented in this article allows for the maintenance of both small and large photovoltaic solar plants without the need for periodic on-site inspections. 
Thanks to the revisit period of the satellites, different spectral indices can be calculated periodically and free of charge to detect those areas of the installation that require maintenance due to the presence of water or vegetation. The process of downloading and calculating these indexes is performed automatically thanks to a Python script implemented in the proposed SDI. Likewise, the integration of Landsat- 8 and Sentinel-2 data is based on the Open Data Cube standard and the Local Nested Grid tool developed. This integration allows for maximum use of these products in geometric, radiometric, and temporal terms. In this way, the INSPECTORMAP user does not have to perform any calculations; they only have to analyze the results offered by the tool and be aware of the warnings the tool automatically generates when certain thresholds are exceeded.

Although the estimation of spectral indices for the detection of anomalous vegetation and water bodies is very useful, it must be considered that, in some cases, the quantified surfaces are not sufficiently precise. For this reason, the SDI INSPECTORMAP serves as a support tool to aid the maintenance operators to know the vegetation activity and water bodies growth in the surroundings of photovoltaic plants, which can be a potential risk for the operation of these facilities. As has been demonstrated with the estimation of the areas affected by vegetation, in most cases, the tool is very useful to know exactly the location where the operator will proceed to withdrawal.

Although there are several indices for estimating water bodies by satellite images, this contribution confirms that the NDWI index allows for a precise estimation of the affected areas compared to other indices such as the SWI, which tends to overestimate the areas with presence of water. As has been shown, the improved resolution of satellite imagery allows a more precise quantification. This improvement in precision is key for sensitive cases of large floods, in which a highly precise quantification of the affected area is required without involving a large computational expense.

Author Contributions: Conceptualization, E.R.d.O. and D.G.-A.; methodology, E.R.d.O., M.S.-A., S.D.P. and D.G.-A.; software, E.R.d.O.; validation, M.S.-A. and S.D.P.; formal analysis, D.G.-A., M.S.-A and S.D.P.; writing—original draft preparation, M.S.-A.; writing—review and editing, S.D.P. and D.G.-A. All authors have read and agreed to the published version of the manuscript.

Funding: This research was funded by the CDTI, grant number IDI-20170947.

Institutional Review Board Statement: Not applicable.

Informed Consent Statement: Not applicable.

Acknowledgments: This work was financed by the CDTI, belonging to the Ministry of Science and Innovation of Spain, through the call for CIEN strategic projects within the framework of the Project INSPECTOR: industrial inspection and maintenance of complex or unattended facilities. Authors would like to thank Junta de Castilla y León with the Fondo Social Europeo for the financial support given through programs for human resources (EDU/1100/2017).

Conflicts of Interest: The authors declare no conflict of interest.

\section{References}

1. Bakirtas, T.; Akpolat, A.G. The relationship between energy consumption, urbanization, and economic growth in new emergingmarket countries. Energy 2018, 147, 110-121. [CrossRef]

2. Global Energy Statistical Yearbook. 2021. Available online: https://yearbook.enerdata.net/renewables/renewable-in-electricityproduction-share.html (accessed on 8 November 2021).

3. International Energy Agency. Global Energy Review. 2019. Available online: https://www.iea.org/reports/global-energyreview-2019 (accessed on 8 November 2021).

4. International Energy Agency. Data and Statistics. Available online: https: / www.iea.org/data-and-statistics?country=WORLD\& fuel=Energy \%20consumption\&indicator=Electricity\%20consumption (accessed on 17 November 2021).

5. IRENA. Global Energy Transformation: A Roadmap to 2050; International Renewable Energy Agency: Abu Dhabi, United Arab Emirates, 2018.

6. Balasubramanian, K.; Thanikanti, S.B.; Subramaniam, U.; Sudhakar, N.; Sichilalu, S. A novel review on Optimization Techniques used in Wind Farm Modelling. Renew. Energy Focus 2020, 35, 84-96. [CrossRef] 
7. Honrubia-Escribano, A.; Ramirez, F.J.; Gómez-Lázaro, E.; García-Villaverde, P.M.; Ruiz-Ortega, M.J.; Parra-Requena, G. Influence of solar technology in the economic performance of PV power plants in Europe. A comprehensive analysis. Renew. Sustain. Energy Rev. 2018, 82, 488-501. [CrossRef]

8. Mercom India. Available online: https://mercomindia.com/world-largest-solar-park-bhadla/ (accessed on 13 October 2021).

9. Saur Energy International. Available online: https://www.saurenergy.com/solar-energy-news/huawei-smart-pv-solutionhighlights-role-in-worlds-largest-pv-plant (accessed on 13 October 2021).

10. PV Magazine. Available online: https://pv-magazine-usa.com/2020/10/02/worlds-largest-solar-plant-goes-online-in-china/ (accessed on 13 October 2021).

11. Nammatumkur. Available online: https://nammatumkur.com/worlds-largest-solar-power-park-at-karnataka-is-fullyoperational/ (accessed on 26 October 2021).

12. Mercom India. Available online: https://mercomindia.com/pavagada-solar-park-operational-december-2019/ (accessed on 25 October 2021).

13. Hernández-Callejo, L.; Gallardo-Saavedra, S.; Alonso-Gómez, V. A review of photovoltaic systems: Design, operation, and maintenance. Sol. Energy 2019, 188, 426-440. [CrossRef]

14. Gallardo-Saavedra, S.; Hernández-Callejo, L.; Duque-Pérez, O. Technological review of the instrumentation used in aerial thermographic inspection of photovoltaic plants. Renew. Sustain. Energy Rev. 2018, 93, 566-579. [CrossRef]

15. Catalano, A.P.; Scognamillo, C.; Guerriero, P.; Daliento, S.; d'Alessandro, V. Using EMPHASIS for the Thermography-Based Fault Detection in Photovoltaic Plants. Energies 2021, 14, 1559. [CrossRef]

16. Li, B.; Delpha, C.; Diallo, D.; Migan-Dubois, A. Application of Artificial Neural Networks to photovoltaic fault detection and diagnosis: A review. Renew. Sustain. Energy Rev. 2021, 138, 110512. [CrossRef]

17. Irons, J.R.; Dwyer, J.L.; Barsi, J.A. The next Landsat satellite: The Landsat data continuity mission. Remote Sens. Environ. 2012, 122, 11-21. [CrossRef]

18. Ahmed, K.R.; Akter, S. Analysis of landcover change in southwest Bengal delta due to floods by NDVI, NDWI and K-means cluster with Landsat multi-spectral surface reflectance satellite data. Remote Sens. Appl. Soc. Environ. 2017, 8, 168-181. [CrossRef]

19. Piedelobo, L.; Ortega-Terol, D.; Del Pozo, S.; Hernández-López, D.; Ballesteros, R.; Moreno, M.A.; Molina, J.L.; González-Aguilera, D. HidroMap: A new tool for irrigation monitoring and management using free satellite imagery. ISPRS Int. J. Geo-Inf. 2018, 7, 220. [CrossRef]

20. Hernández-López, D.; Piedelobo, L.; Moreno, M.A.; Chakhar, A.; Ortega-Terol, D.; González-Aguilera, D. Design of a Local Nested Grid for the Optimal Combined Use of Landsat 8 and Sentinel 2 Data. Remote Sens. 2021, 13, 1546. [CrossRef]

21. Open Data Cube. Available online: https://www.opendatacube.org/ (accessed on 2 November 2021).

22. Main-Knorn, M.; Pflug, B.; Louis, J.; Debaecker, V. Calibration and validation plan for the L2A processor and products of the Sentinel-2 mission. In Proceedings of the International Symposium on Remote Sensing of Environment (ISRSE), Berlin, Germany, 11-15 May 2015; Volume 40, pp. 1249-1255. [CrossRef]

23. Czapla-Myers, J.; McCorkel, J.; Anderson, N.; Thome, K.; Biggar, S.; Helder, D.; Aaron, D.; Leigh, L.; Mishra, N. The ground-based absolute radiometric calibration of Landsat 8 OLI. Remote Sens. 2015, 7, 600-626. [CrossRef]

24. USGS Search and Download Service. Available online: https:/ / ers.cr.usgs.gov (accessed on 27 September 2021).

25. OpenSearch Protocol. Available online: http://www.opensearch.org/Home (accessed on 14 September 2021).

26. Martínez-Fernández, J.; González-Zamora, A.; Sánchez, N.; Gumuzzio, A.; Herrero-Jiménez, C.M. Satellite soil moisture for agricultural drought monitoring: Assessment of the SMOS derived Soil Water Deficit Index. Remote Sens. Environ. 2016, 177, 277-286. [CrossRef]

27. Ryu, J.H.; Han, K.S.; Hong, S.; Park, N.W.; Lee, Y.W.; Cho, J. Satellite-based evaluation of the post-fire recovery process from the worst forest fire case in South Korea. Remote Sens. 2018, 10, 918. [CrossRef]

28. Kaplan, G.; Avdan, U. Object-based water body extraction model using Sentinel-2 satellite imagery. Eur. J. Remote Sens. 2017, 50, 137-143. [CrossRef]

29. Carlson, T.N.; Ripley, D.A. On the relation between NDVI, fractional vegetation cover, and leaf area index. Remote Sens. Environ. 1997, 62, 241-252. [CrossRef]

30. $\mathrm{Xu}, \mathrm{H}$. Modification of normalised difference water index (NDWI) to enhance open water features in remotely sensed imagery. Int. J. Remote Sens. 2006, 27, 3025-3033. [CrossRef]

31. McFeeters, S.K. The use of the Normalized Difference Water Index (NDWI) in the delineation of open water features. Int. J. Remote Sens. 1996, 17, 1425-1432. [CrossRef]

32. Versaci, M.; Calcagno, S.; Morabito, F.C. Image contrast enhancement by distances among points in fuzzy hyper-cubes. In Proceedings of the International Conference on Computer Analysis of Images and Patterns, Valletta, Malta, 2-4 September 2015; Springer: Cham, Switzerland, 2015; pp. 494-505. [CrossRef]

33. Arozarena, A.; Villa, G.; Valcárcel, N. The National Aerial Ortophoto Program in Spain (PNOA). In Proceedings of the International Cartographic Conference, La Coruña, Spain, 9-16 July 2005.

34. Haklay, M.; Weber, P. Openstreetmap: User-generated street maps. IEEE Pervasive Comput. 2008, 7, 12-18. [CrossRef]

35. Instituto Geográfico Nacional. Available online: https://www.ign.es/web/cbg-area-cartografia (accessed on 13 October 2021).

36. Jiang, W.; Ni, Y.; Pang, Z.; He, G.; Fu, J.; Lu, J.; Yang, K.; Long, T.; Lei, T. A new index for identifying water body from SENTINEL-2 satellite remote sensing imagery. ISPRS Ann. Photogramm. Remote Sens. Spat. Inf. Sci. 2020, 3, 33-38. [CrossRef] 